\title{
Commentary: All members of $\beta$-blocker house on probation!
}

\author{
Frank A. Baciewicz, Jr, MD
}

\footnotetext{
From the Department of Cardiothoracic Surgery, Michael and Marian Ilitch Department of Surgery, Wayne State University School of Medicine, Detroit, Mich.

Disclosures: Author has nothing to disclose with regard to commercial support.

Received for publication Jan 9, 2019; accepted for publication Jan 10, 2019; available ahead of print March 7, 2019.

Address for reprints: Frank A. Baciewicz, Jr, MD, Harper Hospital, 3990 John R St, Detroit, MI 48201 (E-mail: fbaciewi@dmc.org).

J Thorac Cardiovasc Surg 2019;158:1598-9

$0022-5223 / \$ 36.00$

Copyright $\Subset 2019$ by The American Association for Thoracic Surgery

https://doi.org/10.1016/j.jtcvs.2019.01.035
}

Although not the double secret probation given by Dean Wormer to the rowdy members of Delta House in the 1978 National Lampoon's movie Animal House, ${ }^{1}$ Schubert and coauthors ${ }^{2}$ recommend putting $\beta$-blockers on probation for patients undergoing elective aortic valve replacement (AVR). In their study, published in this issue of the Journal as "Preoperative $\beta$-Blocker Use Correlates with Worse Outcomes in Patients Undergoing Aortic Valve Replacement", Schubert and coauthors ${ }^{2}$ collected data on 7380 patients undergoing elective AVR between 2002 and 2016 in the Commonwealth of Virginia. The AVR cases excluded emergency cases and those performed for endocarditis. The patients were divided into 2 groups: those receiving a preoperative $\beta$-blocker $(n=3911)$ and those not given a preoperative $\beta$-blocker $(\mathrm{n}=3469)$. Compared to the patients without $\beta$-blockade, the patients with $\beta$-blockade were older (average age, 70 years vs 68 years), had a greater prevalence of high blood pressure $(84.8 \%$ vs $64.6 \%)$, had a higher incidence of myocardial infarction (MI) $(13.2 \%$ vs $6.3 \%$ ), had a higher likelihood of recent congestive heart failure $(46.8 \%$ vs $35.6 \%)$, had an increased risk of diabetes mellitus (34.2\% vs $24.0 \%$ ), were more likely to be dialysis dependent $(2.2 \%$ vs $1.4 \%)$, and had a higher incidence of percutaneous coronary intervention $(11.9 \%$ vs $6.2 \%)$. Not surprisingly, the patients who received $\beta$-blockers had a higher Society of Thoracic Surgeons (STS) predicted rate of mortality $(2.3 \%$ vs $1.9 \%)$ and also a greater STS predicted rate of major morbidity $(15.8 \%$ vs $12.9 \%)$.

Because the $\beta$-blocker cohort appeared to be a higher risk group, Schubert and coauthors ${ }^{2}$ propensity matched 4592 of these patients with 2296 who were taking a preoperative $\beta$-blocker and a similar number who were not receiving a preoperative $\beta$-blocker. The propensity-matched $\beta$-and non- $\beta$-blocker groups did not have statistically different STS predicted rate of mortality $(2.8 \%$ vs $2.4 \%)$ or STS predicted rate of major morbidity $(14.4 \%$ vs $12.7 \%)$. The $\beta$-blocker group had significantly increased incidences of cardiac arrest $(2.1 \%$ vs $1.3 \%)$, transfusion $(38.2 \%$ vs $33.8 \%)$, dialysis-dependent renal insufficiency $(1.7 \%$ vs hospitalization. tion of $60 \%$.

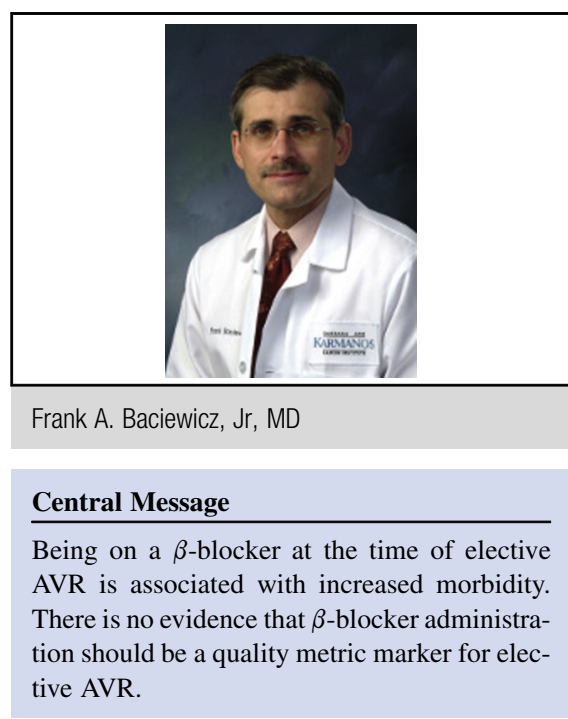

See Article page 1589.

$0.9 \%)$, and postoperative atrial fibrillation $(26.9 \%$ vs $23.4 \%$ ). The $\beta$-blocker group also had increased lengths of stay both in the intensive care unit and for the entire

Because of these significant differences in postop morbidity, Schubert and coauthors ${ }^{2}$ advise against giving $\beta$-blockers before elective AVR. In their perspective statement, they add the caveat that one should consider discontinuing a $\beta$-blocker for patients scheduled for elective AVR.

Even after the statistically complex tools used for propensity matching, there were more patients in the $\beta$-blocker group who had a greater body mass index $(29.1 \%$ vs $28.4 \%$ ), more patients with diabetes mellitus $(29.7 \%$ vs $29.0 \%)$, more patients on statin therapy $(56.6 \%$ vs $52.3 \%$ ), more patients receiving dialysis (2.1\% vs $1.4 \%$ ), more patients with a previous cerebrovascular accident $(14.6 \%$ vs $13.5 \%)$, more patients with myocardial infarction $(8.7 \%$ vs $8.0 \%)$, more patients with previous coronary artery bypass grafting (CABG; $9.1 \%$ vs $8.0 \%$ ), and more patients with coronary artery disease (CAD; $21.0 \%$ vs $19.9 \%$ ). Patients in both groups had a similar ejection frac-

Even bowing to propensity matching, is it possible that taking a $\beta$-blocker is simply a marker for CAD, cerebrovascular disease, or renal vascular disease? Were the $\beta$-blocked house brothers members of a sicker fraternity?

Because $\beta$-blockers may be a surrogate for patients with coronary disease, why not exclude from the analysis all 
patients who had previous CABG, myocardial infarction or CAD? Removing these patients potentially helped by $\beta$-blocker treatment would eliminate a possible confounder.

If $\beta$-blockers predict postoperative morbidity, the $\beta$-blocker effect might more likely manifest itself in the sickest patients with low ejection fraction undergoing AVR. A subanalysis of patients undergoing AVR with ejection fraction of less than $30 \%$ might demonstrate an even greater disadvantage to taking preoperative $\beta$-blockers. Conversely, if the low-ejection fraction AVR group has a preponderance of $\mathrm{CAD}$, MI, or cerebrovascular accident, then the $\beta$-blocker group might show less postoperative morbidity. This low-ejection fraction analysis might mirror the favorable results demonstrated in patients undergoing CABG with an ejection fraction of less than $30 \%$ receiving preoperative $\beta$-blockers. ${ }^{3}$

The University of Virginia group's 2013 analysis of CABG outcome ${ }^{4}$ concluded that preoperative $\beta$-blockers should not be a quality metric marker. Their group demonstrated similar mortality and morbidity in patients undergoing $\mathrm{CABG}$ regardless of whether or not they were taking a preoperative $\beta$-blocker. Evidence is lacking for initiating a $\beta$-blocker several days before elective AVR or in the operating room as a quality metric marker. How many patients were administered $\beta$-blockers solely as a potential quality metric marker is not provided in the article of Schubert and coauthors. ${ }^{2}$ Similarly, evidence for discontinuing $\beta$ blockers for all patients scheduled for elective AVR is not available and will be challenging to obtain.

Transcatheter AVR (TAVR) was first performed by Dr Alan Cribier in $2002^{5}$ and became a common surgical alternative in 2008 to 2012. It would be interesting to know the percentage of patients undergoing TAVR who were receiving a $\beta$-blocker preoperatively, and whether the outcomes were affected. Regarding the Virginia experience, the availability of TAVR in the period reviewed probably decreased the number of high-risk patients offered elective AVR. If the assumption is made that many of the high-risk patients undergoing TAVR were receiving a $\beta$-blocker, then the higher risk patients were subtracted from the open AVR pool. These higher risk patients on $\beta$-blockers who were excluded from the propensity-matched elective AVR cohort may have further shifted the argument in favor of the position of Schubert and coauthors. ${ }^{2}$

The intensive care unit stay was longer in the $\beta$-blocker group. Nevertheless, the hospital costs for the $\beta$-blocker and non- $\beta$-blocker groups were similar $(\$ 32,253$ vs $\$ 32,746)$. Why did the increased incidence of cardiac arrest, transfusion, dialysis-dependent renal disease, and atrial fibrillation not result in higher hospital costs for the $\beta$-blocker group?

Schubert and coauthors ${ }^{2}$ have made their point that adding $\beta$-blockers to elective AVR likely does not improve outcomes and may predict increased morbidity. I agree that the members of $\beta$-blocker house should remain on Dean Wormer's probation list, but I am not in favor of expelling them from the cardiac care institute.

\section{References}

1. Universal Pictures. National Lampoon's Animal House [film]; 1978.

2. Schubert SA, Hawkins RB, Mehaffey JH, Fonner CE, Rich JB, Speir AM, et al Preoperative $\beta$-blocker use correlates with worse outcomes in patients undergoing aortic valve replacement. J Thorac Cardiovasc Surg. 2019;158:1589-97.e3.

3. Ferguson TB Jr, Coombs LP, Peterson ED; Society of Thoracic Surgeons National Adult Cardiac Surgery Database. Preoperative beta-blocker use and mortality and morbidity following CABG surgery in North America. JAMA. 2002;287:2221-7.

4. LaPar DJ, Crosby IK, Kron IL, Fonner E Jr, Rich JB, Speir AM, et al. Preoperative beta-blocker use should not be a quality metric for coronary artery bypass grafting. Ann Thorac Surg. 2013;96:1539-44; discussion 1544-5.

5. Cribier A, Eltchaninoff H, Bash A, Borenstein N, Tron C, Bauer F, et al Percutaneous transcatheter implantation of an aortic valve prosthesis for calcific aortic stenosis: first human case description. Circulation. 2002;106: 3006-8. 